\title{
Use of Digital Media in Higher Education across Country Contexts: A Comparison between Germany and Thailand
}

\author{
https://doi.org/10.3991/ijet.v16i20.24263 \\ Christin Grothaus $^{1(\bowtie)}$, Carina Dolch ${ }^{2}$, Olaf Zawacki-Richter ${ }^{2}$ \\ ${ }^{1}$ Mahidol University International College, Bangkok, Thailand \\ ${ }^{2}$ Carl von Ossietzky University Oldenburg, Oldenburg, Germany \\ christinmarie.gro@mahidol.ac.th
}

\begin{abstract}
Digital media and educational technologies have the potential to support an increasing internationalization of education, connecting students across borders and in international classrooms. However, practitioners and scholars need to further discuss the adaptation of online learning pedagogies to cultural contexts students operate in. Focusing on two countries that differ noticeably in cultural value orientations, this study compares primary data of media use and attitudes of higher education students from Thailand with secondary data of students from Germany. Acceptance, frequency of use and perceived usefulness of various digital media and technologies for academic purposes were assessed. The study further measured ownership of digital devices as well as study related activities performed via social media and digital devices. Results disclosed a stronger preference for and more frequent use of entertainment media and collaborative tools among Thai learners. German students showed higher acceptance of office tools and performed fewer study related tasks via social media. Both groups found various digital media and educational tools more useful as compared to how often such were used. These and further findings are discussed considering the possible influence of educational-, cyber- and national culture as well as of student demographics.
\end{abstract}

Keywords - Germany, Thailand, media usage, culture, digital technology, digital media, online learning, higher education

\section{Introduction}

Universities increasingly include aspects of internationalization in their agendas, aiming to attract international students, to grow cross-border activities and to branch campuses and education hubs [1,2]. Digital media, tools and services can support such efforts, enabling students to study across borders. Moreover, providing a variety of digital media can help institutions and lecturers to better respond to students' individual learning styles, needs and requirements in diverse classroom settings. Scholars have shown that foreign exchange students can benefit from blended learning approaches [3] as well as that cross-cultural competency can be developed with help of emerging tech- 
nologies [4]. Further, online learning technologies can support those students in developing countries who cannot afford to commute or who look for lower study fees of local programs or online distance programs. The later would allow developing countries to keep their talents and prevent the migration of relatively highly educated students who aim to receive better education abroad [5].

While, in many developing countries, such as in the region of Asia, the integration of new technologies into the context of higher education happens at a fast pace, pedagogies need to be adapted to the context students operate in [6]. Countries that differ clearly in cultural value orientations deserve particular attention as such values may influence students' use of and attitudes towards digital media and tools. Many South East Asian countries, such as Thailand, have been associated with stronger values for collectivism, power distance and femininity as compared to the majority of Western country contexts, such as Germany [7]. Scholars, however, have paid less attention to the use of and attitudes towards learning technologies across country contexts. Those who have examined the individualism-collectivism dimension $[8,9,10]$ have associated individualism with the encouragement of values for independence and self-reliance, while in collectivist societies interdependence is more regularly encouraged. Such values could, for example, influence preference for collaborative tools. A comparison of Facebook usage across countries in Asia revealed a preference for social media in education [11].

The book "The Asian Learner" [12], which compromises various articles that stress the role of culture and demographics in distance learning, presents conflicting findings. Articles, on the one hand, highlight how individualistic values and lower acceptance of unequal power distributions in the West affect self-management, autonomous learning as well as critical thinking. Collectivist values, on the other hand, can encourage knowledge transmission, memorization and synthesis. However, Murphy and Yuen [13], who discussed the development of online course materials, argued that, while there is a common perception that Asian learners prefer rote learning, scholars in countries such as China have found otherwise, concluding that opportunities to engage in deep learning should be offered. Buraphadeja \& Kumnuanta [14], who assessed peers tutoring to support self-paced learning among Thai students, highlighted that students' value to respect the teacher, could be an obstacle towards e-learning. Learners would become passive and expect the teacher to provide knowledge for them. Ngampornchai \& Adams [15], however, found slightly positive perceptions towards e-learning among Thai students, particularly for those with higher levels of self-regulation.

One explanation for such contrasting findings could be that values associated with online cultures or the expression of those don't equal values and their affects on behavior linked to the offline context. While national cultures can be described as shared practices, attitudes, ways of thinking and values in a national context [7], digital cultures or cybercultures [16] represent such patterns in virtual spaces, which, similar to national values, may leap into educational institutions and influence educational cultures. Scholars have emphasized the need to further study the role of online cultures as well as hybrid cultures, which fuse online and offline norms, instead of just assuming that national values affect face-to-face learning in the same way as online learning does 
[17]. As a core characteristic of cybercultures, Lévy [16] identified a continuous renewal of interpretations of shared attitudes, values and behaviors in virtual communities. Scholars should pay further attention to the role of national culture in the context of online media for study purposes in higher education, whilst considering the possibility of emerging cybercultures.

Next to differences in culture, student demographics, such as differences in age and gender have shown to affect media usage $[18,19]$. University students in Thailand are on average younger and more likely female [20] as compared to those in Germany [21]. Differences in age demographics could be further linked to cultural value orientations. For example, values for power distance and uncertainty avoidance in Thailand [7] can encourage parents to support a more direct and predictable educational path of their children without any interruptions, which in turn can explain younger student cohorts. A non-traditional educational path where students interrupt or postpone their studies, planning family or work next to studying, is common in Germany [22].

Though educational institutions in Thailand and Germany have received support to develop online learning [6, 23], stakeholders remain skeptical [24]. A better understanding of how to integrate digital media and services, considering the context of the society and culture students operate in, could positively affect engagement of educators in local and international contexts. It could further decrease existing skepticism of stakeholders involved. Despite the possible influence of culture and demographics on online learning, there is a lack of scholarly efforts comparing media usage and online learning across country contexts and even more so of studies discussing identified differences with reference to the country contexts, as review studies show [25, 26]. Furthermore, scholars need to pay attention to understudied regions, such as that of South East Asia. Findings could support collaboration across countries and institutions in the process of a growing internationalization of education. Scholars have stressed that efforts in internationalization of education should consider differences in education, instead of paying attention to quantifying factors, such as coverage of regions, languages and programs only [27].

The following section elaborates on the current state of digital education in Thailand and Germany.

\subsection{Digital higher education in Thailand}

In a worldwide media usage assessment report released in 2018 Thailand ranked number one, with an average of 9.38 hours spent online per day and took fourth place with 3.5 hours of daily social media use [28]. In 2018 the "Digital Government Agency" was formed with the aim to increase digital knowledge and skills of people living in Thailand through an initiative titled "Thailand 4.0" which included efforts in the fields of higher education $[6,29]$. Thailand's changing demographics further reinforce such initiatives. The United Nations identified Thailand as the world's third most rapidly ageing country with a sharp decline in birth rates [30]. The Council of University Presidents of Thailand (CUPT) stated that while in 2018 there were 300,000 available seats, students applied for only around 230,000 which was related to a declining birth rate 
[31]. Online learning was highlighted as a potential solution in the quest to increase student numbers.

However, while in Thailand support for online education has been increasing noticeably, educational stakeholders may not equally follow up with such trends. The question arises if Thai students who are growing up using digital media frequently are more open to use media and tools for educational purposes and if so what media usage patterns and preferences exist. Scholars have started to investigate in media usage in the context of Thailand. However, such studies more often focus on either the assessment of one or a limited number of tools or of general satisfaction with e-learning. Scholars have focused on antecedents $[32,33,34]$ as well as on the effectiveness or outcomes of particular tools and approaches $[35,36]$. Studies have discussed overall readiness, satisfaction and acceptance of e-learning [37, 38, 39, 40] but have neglected to consider a variety of tools. Further, research has paid more attention to media usage in people's everyday lives rather than in the context of education. Studies that discuss the use of various media for higher education purposes date back to 2013 [41] and do not focus on explaining country specific differences.

\subsection{Digital higher education in Germany}

In Germany, similar to Thailand, the Federal Government has supported the digitalization of higher education. The potential of online learning to innovate the academic landscape in Europe [23] was further amplified by the "Digital agenda 2014-2017", which aimed to prepare future and current employees for the digitalization of the workplace in Germany [42]. Further efforts are visible with the funding of research projects in the field of online learning and initiatives to develop digital competencies [43]. Moreover, in Germany heterogenous groups with different student profiles have received support, such as those of part-time students, who need to organize their studies next to their work $[44,22]$.

However, similar to Thailand, despite these developments, sustainable long-term growth integrating digital learning into mainstream higher education has still not happened. The "Index of Readiness for Digital Lifelong Learning" by the Centre for European Policies Studies (CEPS), comparing European countries, placed Germany on the last rank, which has received criticism such as that of an under-investment in digital infrastructure, reflecting an underlying skepticism towards digital technologies [24].

Two systematic reviews reflect upon German as well as international students' media usage and usefulness in higher education between 2010-2017 [45, 46]. Steffens et al. [46] highlighted that the majority of media usage studies focus on frequency of use and possession of media and tools [47]. Over the years of 2012, 2015 and 2018 a comprehensive survey among German students $(N=5,572)$ was conducted assessing student's preferences and frequency of use of media, tools and services as well as their use of mobile phones and social media across 42 German universities [19]. Students in the 2018 sample showed highest acceptance rates for search engines, followed by instant messaging, email accounts, word-processing programs, computer working spaces at home and PDF readers. The learning management platform fell from place 4 to 7 from 
2012 to 2018. Such results show a focus on traditional media and office programs among the German students.

\subsection{Digital higher across country contexts - A comparison between Germany and Thailand}

Both, in Germany and Thailand, there have been attempts of several stakeholders to support the integration of digital media into higher education. Considering challenges, such as the reluctance of lecturers and students to introduce new educational tools as well as low self-efficacy when using new technologies, investigating media usage and perceived usefulness can help to guide in choice of tools across country contexts.

Though scholars have investigated media use in higher education in both countries, as to our best knowledge, none have compared media and preferences usage across these country contexts. Review studies $[25,26]$ show that scholars who discuss the role culture in online learning do not focus on various media in one study but instead on particular tools or activities. Studies that have assessed a number of tools across country contexts $[41,18]$ do neither focus on the influence of national cultural values, nor oon cybercultures.

Responding to this gap in the literature, the purpose of this study is to assess student's perceptions and use of digital media and services for their studies across two countries differing noticeably in cultural value orientations as to discuss the possible influence of the country context on use of and preference for digital media and technologies. Using the same questionnaire, secondary data collected of German higher education students in 2018, was compared with primary data of Thai higher education students in 2020. Ownership of devices, perceived usefulness and use of numerous media, tools and services as well as activities performed via social media and mobile devices were assessed as to answer the following research questions:

- Do German and Thai HE students differ in their possession of digital devices and in duration of Internet use?

- How does usage and acceptance of media, e-learning tools and services for study purposes differ between Thai and German HE students?

- What study related activities do German and Thai HE students perform with help of mobile devices and social networks?

\section{Methodology}

\subsection{Sample and instrument}

To answer the above questions, we compare secondary data collected across 42 German higher education institutions between October and December $2018(N=1,928)$ with primary data collected in Thailand between February and March $2020(N=192)$. In Germany data was collected with help of a mailing list of the project leaders and coordinators of the BMBF program 'Offene Hochschulen' ['Open Universities'] and 
of the project 'eCompetence and Utilities for Learners and Teachers' (eCULT). The online questionnaire was distributed via the homepage and the learning management system (LMS) of the universities. Participation was voluntary and self-recruited. For the data collection in Thailand, basically, the same online survey instrument [48] was used for both countries. Data collection started shortly before the Corona Virus outbreak in February 2020 and was conducted by the principle author. As the outbreak affected university instruction with classes being conducted fully online from March 2020 onwards, data collected after universities went online was not included as not to distort the findings.

Data in Thailand was collected at a university that represents the demographics of university students in Thailand in terms of age and gender distribution. Students in Thailand are in average younger than German students with a higher ratio of female to male $[20,21]$. The German sample included $65 \%$ female and $35 \%$ male, while the Thai sample consisted of $71 \%$ female, $27 \%$ male and $2 \%$ of a non-binary gender orientation. While the average age of the German sample was $25(S D=6.65)$ the average age of the Thai sample was $19(S D=1.46)$. In the German sample $64 \%$ of the students had a job at some point next to their studies, whereas this was the case for only $6 \%$ of the Thai students (see Table 1). While our sample reflects an average Thai student in terms of age and gender, it does represent upper-middle class students only as we selected an international college with study fees higher than local programs. As it is more likely that students of higher income have access to technologies, our sample allowed us to elaborate on various media usage patterns.

Table 1. Demographics of German and Thai students

\begin{tabular}{|l|c|c|}
\hline \multicolumn{1}{|c|}{ Demographics } & German sample & Thai sample \\
\hline Number & 1,928 & 192 \\
\hline Age & $25(\mathrm{SD}=6.65)$ & $19(\mathrm{SD}=1.46)$ \\
\hline Gender & $\begin{array}{c}65 \% \text { female, } \\
35 \% \text { male }\end{array}$ & $\begin{array}{c}71 \% \text { female, } 27 \% \text { male, } 2 \% \\
\text { non-binary }\end{array}$ \\
\hline Subject (majority) & $\begin{array}{c}33 \% \text { Engineering, } \\
24 \% \text { Economics, Law }\end{array}$ & $\begin{array}{c}37 \% \text { Business Studies, } 27 \% \\
\text { Science }\end{array}$ \\
\hline Online-learning, blended Learning & $3 \%$ online, $8 \%$ blended learning & All in traditional classrooms \\
\hline Work next to studying & $64 \%$ & $6 \%$ \\
\hline Average semesters/Trimesters & 5 semesters & 3 trimesters \\
\hline
\end{tabular}

At the time of the survey German students had studied 5 semesters and Thai students 3 trimester on average. While in the German sample $3 \%$ studied online and $8 \%$ in blended learning settings, in the Thai sample there were no students in either one of these categories. Most of the students in the Thai sample studied Business Studies (37 $\%$ ) and Science $(27 \%)$ as well as Humanities and Languages (14\%) which reflects fields of studies among the most commonly offered in Thai universities. In the German sample most students studied subjects from the field of Engineering (33\%) as well as Economics and Law (24\%). 
Survey items related to media, tools and services were classified based on the on the media typology of Grosch and Gidion [49]. Media provided by universities as e-learning tools and services as well as general web tools and services used in everyday lives for communication and information sharing were included. Students were asked to assess each of the items in terms of frequency of use $(5=$ almost every day; $4=$ a few times a week; 3 = between once a week and once a month; $2=$ less than once a month; $1=$ never $)$ and usefulness for academic purposes $(5=$ very useful $-1=$ not useful at all), using Likert scales. Any tools, media and services that students were not familiar with were counted as missing values.

For the survey in Thailand examples of tools and services from the German instrument were replaced with examples familiar to Thai students (e.g. Germany: Chat/Instant Messaging (e.g. WhatsApp, Threema); Thailand: Chat/Instant Messaging (e.g. Line)). Furthermore, some items that Thai students are not familiar with were removed (e.g., Etherpads) and a few tools that recently emerged (e.g., virtual bulletin boards) were added. In the German study, a total of 57 media, tools and services were queried; in the Thai study, it was 56.

In order to identify which items should be taken out, added or adapted we relied on pre-surveys we conducted among 150 Thai students as well as on expert interviews [50]. These were led with four Thai university staff members responsible for e-learning strategies and their implementation, such as the Assistant Dean of the University.

The German survey was conducted in German language. For the Thai survey, the German questionnaire was translated to English by the author(s) and into Thai language by professional translators familiar with the technical terms of the survey. Back translation helped to clarify which translations were not accurate. The survey included both the English and the Thai language version. Ethics approval was obtained from the Institutional Review Board of Mahidol University (approval number COA. No. 2020/02054).

\subsection{Data analysis and limitations}

In order to compare the German and Thai sample as to answer our research questions descriptive analysis and t-tests are applied. As to assess media acceptance, we computed the mean of usefulness and frequency of use (value usage frequency + value usefulness)/2). Data in Thailand was collected in an international college in Thailand whereas data in Germany was collected across universities. Thai students mostly came from an upper-middle class income background, which is representative for a Thai international college but not for the entire student population. While we did not represent other income groups, both groups had access to Internet and different devices, which allowed us to ask questions regarding perceived usefulness of various media, tools and services in the context of online learning. While students were surveyed in Germany in 2018 and in Thailand in 2020, data was collected in both countries before the Corona Crisis as to be able to compare survey results. 


\section{$3 \quad$ Results}

\subsection{What kind of digital devices do HE students own and how much time to they spend online?}

Thai and German HE students differ significantly concerning the number of digital devices they own $(t(181.87)=-1.98, \mathrm{p}=.049)$. Thai students own 5 different digital devices on average $(M=4.79, S D=2.61)$ while German students own only 4 devices on average $(M=4.39, S D=1.75)$. Nevertheless, students of both countries are well equipped for possible online studies. The great majority of both student groups (Thai $90 \%$, German $98 \%$ ) own smartphones with internet access (see Table 2). With 7.7 hours $(S D=2.51)\left(M_{\text {Germans }}=4.82, S D_{\text {Germans }}=3.95\right)$ Thai students spend significantly more time online per day $(t(182.97)=-9.25, \mathrm{p}<.001)$. Of the time spent online Thai students use the mobile internet for 5.74 hours on average $(S D=3.61)$ while German students only spend 3.47 hours on average $(S D=11.47)$ using the mobile internet $(t(1886)=-2.54, p=.01)$. The noticeably stronger use of the internet among Thai students, paired with a high number of students owning mobile devices, with more Thai students owning laptops, wearables and tablets, shows mobility which can enable to conveniently access class material and to communicate in and outside classrooms.

The two groups further show a noticeable difference in terms of ownership of devices that are not mobile. More German than Thai students own printers (difference 21 $\%$ ) and scanners (difference $25 \%$ ) while Thai students do have access to those. Further, $30 \%$ more Thai students than German students own a digital voice assistant (see Table 2).

Table 2. Ownership of digital media by Thai and German higher education students

\begin{tabular}{|l|c|c|c|}
\hline $\begin{array}{l}\text { Ownership } \\
\text { (Ranked based on difference) }\end{array}$ & Thailand & Germany & Difference \\
\hline Digital Voice Assistance & $57 \%$ & $27 \%$ & $30 \%$ \\
\hline Scanner & $33 \%$ & $58 \%$ & $25 \%$ \\
\hline Printer & $44 \%$ & $65 \%$ & $21 \%$ \\
\hline Tablet-PC & $60 \%$ & $45 \%$ & $15 \%$ \\
\hline Smartphone without Internet access & $26 \%$ & $13 \%$ & $13 \%$ \\
\hline Wearables & $35 \%$ & $22 \%$ & $13 \%$ \\
\hline Notebook/Laptop & $85 \%$ & $95 \%$ & $10 \%$ \\
\hline Desktop-PC & $48 \%$ & $39 \%$ & $9 \%$ \\
\hline Smartphone with Internet access & $90 \%$ & $98 \%$ & $8 \%$ \\
\hline E-Book-Reader & $23 \%$ & $21 \%$ & $2 \%$ \\
\hline
\end{tabular}

While the overall results show that students, and particularly Thai students, are mobile, possessing smart phones and other mobile devices as well as spending a significant chunk of their time every day online, such time may however not always be spent well. 
Therefore, it is important to better understand what particular media, tools and e-learning services students use and prefer for their studies, as outlined in the following section.

\subsection{Which media and e-learning tools and services are used for learning and which are considered useful by HE students of both countries?}

As to compare German and Thai HE students' digital media acceptance of 56 types of media, tools and services (see Table 5 in the Appendix), acceptance scores, resulting from the averaged ratings of the frequency of media use and the perceived usefulness of media for academic purposes ((Usage frequency + Perceived usefulness) / 2), were calculated $[51,50]$. The first two ranks are identical for German and Thai students with search engines ranked first followed by chat/instant messaging. However, t-test results show significant differences for 51 out of 56 tools $(p \leq 0.05)$. Among the first top 10 ranks eight show significant differences between German and Thai students. Thais accept social networks $(M=4.14)$, videos $(M=4.23)$, music $(M=4.05)$ and online translators $(M=4.01)$ significantly more than the group of German students $(M=3.32, M=$ 3.61, $M=3.38)$. German students on the other hand show higher acceptance for PDF readers $(M=4.24)$ and word-processing programs $(M=4.33)$ as compared to the Thai students $(M=3.95)$. Taking a look at the entire list of tools and services, German students accept of all 56 items only nine more than Thai students, with those being: University e-mail account, online library services, PDF reader, word-processing programs, computer working spaces outside of campus, spread sheet software, printed texts, internet-based learning platform and lecture recordings.

According to the above differences, Thai students show stronger acceptance of various tools and among those with the most noticeable differences media for entertainment and leisure purposes. German students on the other hand accept office related media more. The most significant differences in acceptance between both samples we identified for microblogging $\left(M_{\text {German }}=1.53, M_{\text {Thai }}=3.20\right)$, QR Code scanner $\left(M_{\text {German }}\right.$ $\left.=2.04, \underline{M}_{\text {Thai }}=3.59\right)$, collaborative writing tools $\left(M_{\text {German }}=2.17, M_{\text {Thai }}=3.40\right)$, presentation sharing and social networks. All of those are accepted significantly more by Thai students. It is noticeable that among these five most significant differences four are collaborative tools, which can be defined as tools that allow for organizing tasks together through communicating and sharing information when working on a shared goal [52]. As previously identified, Thai students possess more mobile devices such as iPads and eBook readers which could increase their mobility. A similar tendency is shown in acceptance rankings which show lower values for computer spaces at home but more so for those on the campus as well as lower acceptance of printed books among Thai students.

While we aggregated values for perceived usefulness and use as to calculate acceptance values, we also analyzed the two variables separately. We did so by identifying tools and services with the most significant and highest mean differences $(p<.01$ (2-tailed)) for frequency of use in Thailand and in Germany as well as for perceived usefulness. Frequency of use of media for all 56 tools is in average higher among the Thai students $\left(\underline{M}_{\text {Thai }}=2.98, \underline{M}_{\text {German }}=2.24\right)$. Thais also find tools overall much more 
useful $\left(\underline{M}_{\text {Thai }}=3.69, \underline{M}_{\text {German }}=3.17\right)$. The few tools that German students use more frequently than Thais, are external e-mail $\left(M_{\mathrm{German}}=4.31, S D_{\mathrm{German}}=0.91 ; M_{\text {Thai }}=3.89\right.$, $\left.S D_{\text {Thai }}=90\right)$ and university internal e-mail accounts $\left(\underline{M}_{\text {German }}=3.69, S D_{\text {German }}=1.10\right.$; $\left.\underline{M}_{\text {Thai }}=3.03, \underline{S D} \underline{T h a i}_{\text {Thi }}=1.15\right)$, courses e-mailing lists $\left(\underline{M}_{\text {German }}=3.09, S D_{\text {German }}=1.18\right.$; $\left.\underline{M}_{\text {Thai }}=2.71, \underline{S D}_{\text {Thai }}=1.30\right)$ and PDF readers $\left(\underline{M}_{\text {German }}=3.84, S D_{\text {German }}=0.97 ; \underline{M}_{\text {Thai }}=\right.$ $3.43, \underline{S D}$ Thai $=1.16)$. The first three tools that Thai students use significantly more often (collaborative writing tools, microblogging and presentation sharing) are all of collaborative nature which confirms our previously identified trend. When comparing perceived usefulness and frequency of use we found that students overall show higher means of perceived usefulness as compared to frequency of use for all but four media items. In other words, students find various media more useful as compared to how often they use them, which is even more the case for e-learning tools. As compared to general web tools, availability of e-learning tools depends more on the institution, our results show that institutions do not meet student's preferences for various media and tools.

\section{What study related activities do HE students perform with help of mobile devices and social networks across country contexts?}

Both groups of students engage in various study related activities (Table 3) with stronger entertainment media use among Thais students, which confirms our previous findings. Thais use their mobile devices more often for posting texts or pictures (Thai $=68 \%$, German $=45 \%$ ) as well as for listening to music while studying (Thai $=67 \%$ German $=49 \%$ ). While accessing social media platforms just slightly differs across countries in terms of percentage (Thai $=66 \%$, German $=69 \%$ ), it ranks third highest of all activities among the Thai sample but only ranks place 12 for the German sample.

German students search the internet outside of courses (Thai $=62 \%$, German $=86$ $\%$ ), access e-learning platforms (German $=78 \%$, Thai $=60 \%$ ) and send instant messages $(88 \%)$ more often with their digital devices. The most noticeable country differences account for those activities that generally score high for each country. For example, more Thai than German students use their devices to post pictures (difference 23 $\%$ ) while posting pictures shows the third highest frequency for activities Thai students perform with their devices, one percent behind the first two most frequent activities (phone calls and accessing social networks). Noticeably more Thai students use their mobile devices for conducting texts for term papers. This shows that mobile devices are not only used for entertainment purposes but also for more complex tasks, which may be related to our finding that Thais use working spaces outside their homes more often than German students where they may conduct more in-depth activities. 
Paper-Use of Digital Media in Higher Education across Country Contexts: A Comparison between...

Table 3. Use of mobile devices for studying among German and Thai students (ranked based on difference)

\begin{tabular}{|c|c|c|c|}
\hline Mobile activity & German & Thai & Difference \\
\hline Location-based services & $12 \%$ & $47 \%$ & $35 \%$ \\
\hline Searching the internet outside courses & $86 \%$ & $62 \%$ & $-24 \%$ \\
\hline Posting texts or pictures & $45 \%$ & $68 \%$ & $23 \%$ \\
\hline Sending instant messages & $88 \%$ & $67 \%$ & $-21 \%$ \\
\hline Composing texts for term papers & $18 \%$ & $37 \%$ & $19 \%$ \\
\hline Accessing eLearning platform & $78 \%$ & $60 \%$ & $-18 \%$ \\
\hline Listening to music while studying & $49 \%$ & $67 \%$ & $-18 \%$ \\
\hline Sending short messages to instructors (SMS) & $9 \%$ & $26 \%$ & $17 \%$ \\
\hline Library services & $53 \%$ & $38 \%$ & $-15 \%$ \\
\hline Doing research for term papers, presentations etc. & $69 \%$ & $56 \%$ & $-13 \%$ \\
\hline Purchasing books & $35 \%$ & $24 \%$ & $-11 \%$ \\
\hline Sending e-mails to students & $73 \%$ & $64 \%$ & $-9 \%$ \\
\hline Collecting data for term papers etc. & $48 \%$ & $39 \%$ & $-9 \%$ \\
\hline Searching the internet during courses & $74 \%$ & $65 \%$ & $-9 \%$ \\
\hline Sending e-mails to instructors & $74 \%$ & $68 \%$ & $-6 \%$ \\
\hline Taking photographs & $78 \%$ & $72 \%$ & $-6 \%$ \\
\hline Checking course grades & $69 \%$ & $74 \%$ & $5 \%$ \\
\hline Choosing and registering courses & $57 \%$ & $64 \%$ & $5 \%$ \\
\hline Making phone calls & $74 \%$ & $69 \%$ & $-5 \%$ \\
\hline Accessing social networks (e. g. Facebook) & $66 \%$ & $69 \%$ & $3 \%$ \\
\hline Sending short messages to students (SMS) & $36 \%$ & $38 \%$ & $2 \%$ \\
\hline Communicating via e-learning platform & $38 \%$ & $40 \%$ & $2 \%$ \\
\hline
\end{tabular}

While we found that compared to other study related activities on mobile devices social media plays a more important role among Thai students than among German students, Table 4 further shows that there is a noticeable difference with regards to the number of study related tasks students use social media for. More Thai than German students use social networks for all listed study related tasks. The only exception is that of exchanging documents and literature which ranks first with $81 \%$ for both student groups. Further, for all activities, except that of preparing exams and exchanging documents, Thai students show scores which are 19-36\% higher than those of the German sample. Thai students score above $80 \%$ for all the activities except for informing oneself and exchanging on study-related stays abroad, where Germans score below $80 \%$ for all activities except the exchange of documents and literature. 
Paper-Use of Digital Media in Higher Education across Country Contexts: A Comparison between...

Table 4. Use of social networks for studying among German and Thai students (ranked based on difference)

\begin{tabular}{|c|c|c|c|}
\hline Use of social networks & Thailand & Germany & Difference \\
\hline Information and exchange on study-related stays abroad & $77 \%$ & $36 \%$ & $41 \%$ \\
\hline $\begin{array}{l}\text { Finding help for practical matters of studies (searching an accommodation, } \\
\text { work and internship opportunities etc.) }\end{array}$ & $83 \%$ & $59 \%$ & $24 \%$ \\
\hline Establishing and keeping contact & $88 \%$ & $68 \%$ & $20 \%$ \\
\hline Preparing term papers, presentations etc. & $88 \%$ & $68 \%$ & $20 \%$ \\
\hline For questions related to study tasks I do by myself & $91 \%$ & $72 \%$ & $19 \%$ \\
\hline Forming study groups & $85 \%$ & $66 \%$ & $19 \%$ \\
\hline Preparing for exams & $85 \%$ & $76 \%$ & $9 \%$ \\
\hline Exchange of documents and literature & $81 \%$ & $81 \%$ & $0 \%$ \\
\hline
\end{tabular}

\section{Discussion}

Utilizing digital media for higher education to support traditional classrooms, blended learning or distance learning starts with identifying students' preferences and behaviors, which, as our study shows, differ across country contexts. While we cannot conclude that country contexts explain such differences, in the following we suggest possible relationships between country characteristics and media usage which should then be further examined in future studies.

Finding reveal high mobility of Thai students, who possess more devices overall, particularly more mobile devices such as iPads' and wearables, and spend about two more hours daily using the mobile internet. While mobile devices and the use of internet could distract students from their studies, our results show that students utilize media for academic purposes. Adequate use of technologies and the internet can be further supported by institutions. Scholars assessing Thai student teachers, found that institutional situations, such as support by administrators and management support for ICT facilities and the use of ICT media resources and equipment had positive effects on appropriate internet use behavior [53].

When measuring acceptance of 56 media, tools and services, we found higher acceptance of entertainment and leisure media, such as of videos, social networks and music, as well as of collaborative tools among Thai HE students. While traditional media such as word-processing programs, PDF as well email accounts ranked among the top 15 places for both groups, they occupied noticeably higher ranks among German HE students. Thai students mostly use mobile devices for accessing social networks, making phone calls and posting texts and pictures, which confirms a tendency towards use of media that allows for leisure and collaboration. Further, in our acceptance ranking, media such as collaborative writing, social media and discussion groups took higher ranks among the Thai sample. Thai students use social media for all listed study related activities more often than German students, except for the exchange of documents and literature, which ranked first for both groups. Collaborative activities such as, forming study groups with help of social media, ranked third among the Thai sample but took only the $6^{\text {th }}$ rank out of the eight activities among the German HE students. 
The above-mentioned patterns in preferences for entertainment and collaborative media and tools for study purposes may be explained looking at the use of media in students' everyday lives. While Germans use social media and messenger applications outside of university, country rakings place Thailand first in South East Asian and among the top 10 countries worldwide for watch-time [54]. Further, Thailand ranked $7^{\text {th }}$ world wide on social media use with 51 million monthly active social media users [55]. Thais also frequently use emojis and stickers to express feelings and to entertain each other across all ages [55]. If both, lecturers and students are familiar with general web tools, they may more likely use them in the context of higher education for such as collaborative learning purposes.

The stronger preference for and use of entertainment and collaborative tools for study purposes among Thai students may be further explained considering cultural value orientations. The model of cultural dimensions by Trompenaars [56] identified specific cultures (e.g. Germany) which focus more strongly on a separation of personal and work life, whereas diffuse cultures (e.g. Thailand) fuse the two more easily. These cultural dimensions may explain why general media seem to more easily enter education in Thailand than in Germany. Further, enjoyment plays a central role in Thai culture. Having fun ("sanuk") is often referred to as a central characteristic of Thai culture. The word to play ("len") is used in various Thai expressions, such as when one plays to sleep (take a nap), plays to eat (snack), plays ski, plays politics, plays to speak (small talk) and has a play name (nick name) [57]. Lastly, cultural values of collectivism (as compared to individualism) could explain the preference for and use of collaborative tools among the Thai sample. Thailand has shown much lower values of individualism (20) as compared to Germany (67) [7]. In a recent systematic review that assessed studies dealing with the role of culture in collaborative online learning in the context of South East Asia [25] the majority of studies referred to the role of collectivist values. Discussing particular collaborative tools, such as social media, discussion boards or blogs, authors associated increased engagement with ingroup orientation and stressed the importance of maintaining social harmony as well as to increase community building online in collectivist societies.

Further, considering the role of cybercultures, national cultural values, such as those for collectivism and leisure, may be more freely expressed in cyber space. Scholars have emphasized that online environments open up informal spaces for exchange [16]. A mixed method study comparing Austrian and Thai students use of social network sites [58] revealed that Thai students used social networks as informal, comforting spaces in playful and creative way, feeling less restricted to express themselves, whereas Austrian students perceived social networks rather as tools for communication. Further, German students' and lecturers' privacy and data protection using social network sites in Germany may further support why such do not enter education easily [24].

Lastly, demographics may influence preference and use of educational media. Dolch [19] found female German students using devices significantly more for posting texts and pictures and for accessing social networks as well as higher acceptance of social networks among female students. Zawacki-Richter [48] found that the group of so called "German traditional students", who are, among other characteristics, younger, show higher acceptance of entertainment media. However, our findings showed that 
Paper-Use of Digital Media in Higher Education across Country Contexts: A Comparison between...

the differences in preference for and use of entertainment and collaborative media continued to exist across country context when comparing students of the same age groups and gender.

\section{Conclusion}

Our research questions aimed at identifying possible differences in acceptance, perceived usefulness and frequency of use of media as well as in use of social media and digital devices among Thai and German HE students. Findings reveal Thai HE students more often use and more strongly accept collaborative tools and entertainment media for their studies. Cultural value orientations such as those for fun, relaxation and a stronger group orientation as well as tolerance levels towards an overlap of work and private life may explain such preferences and usage. Findings could be utilized to as to encourage the integration of collaborative media to support deep learning through collaboration in online learning environments in the context in Thailand and countries with similar value orientations and demographics.

Results show high mobility among both groups and even more so among Thai students. Such mobility can support online learning using devices in and outside of the classroom. This is particularly the case for e-learning tools. While German students used office tools more frequently, they preferred the use of various tools, findings also revealed that both groups perceive almost all tools as more useful compared to how often they use them. Though educational stakeholders continue to be reluctant to introduce online learning and its various forms and tools, it seems students are not necessarily the ones opposing such changes. The study shows that there is room for the integration of varies types of educational technologies in higher education in Germany and Thailand. However, implementation of media may need to be scaffolded by lecturers as general web tools frequently used for personal purposes different may distract students.

Further research should test the suggested influence of cultural variables such as the relationship between values of collectivism and collaborative tools, between leisure orientation and acceptance of entertainment tools as well the possible influence of values of work life balance on the integration of digital media into higher education. Furthermore, future research should apply qualitative methods to explore explanations for the possible influence of culture on online learning and the use of and preference for digital media more in-depth. Such studies could for example explore how students use collaborative tools for their studies in different cultural contexts or how they perceive the use of entertainment tools across cultures. While we only compared two country contexts, we aimed to provide a framework of reference not only for Germany and Thailand but also for those with similar national value structures as well as educational and cybercultures. 


\section{References}

[1] Knight, J. (2013). Education Hubs: International, Regional and Local Dimensions of Scale and Scope. Comparative Education, 49(3): 374-87. https://doi.org/10.1080/03050068. 2013.803783

[2] Knight, J. (2004). Internationalization Remodeled: Definition, Approaches, and Rationales. Journal of Studies in International Education, 8(1): 5-31. https://doi.org/10.1177/ 1028315303260832

[3] Sheera, H. (2020). Using Blended Learning to Support the Teaching of English as a Foreign Language. Arab World English Journal, 6. https://www./doi/191-211.10.24093/awej/ call6.13

[4] Pudikova, G., Kurilova, A., Movchun, V., Medvedeva, E. \& Kochetkova, G. (2019). Emerging Technologies for Developing Cross-Cultural Competency. International Journal of Emerging Technologies in Learning (iJET), 14(21). https://doi.org/10.3991/ijet.v14i21. $\underline{11194}$

[5] Beine M., Docquier, F. \& Rapoport H. (2001). Brain Drain and Economic Growth: Theory and Evidence. Journal of Development Economics, 64: 275-289. https://doi.org/10.1016/ $\underline{\mathrm{S} 03043878(00) 00133-4}$

[6] Buasuwan, P. (2018). Rethinking Thai Higher Education for Thailand 4.0. Journal of Asian Education and Development Studies, 7(2): 157-173. https://doi.org/10.1108/aeds-07-2017$\underline{0072}$

[7] Hofstede, G. (2011). Dimensionalizing Cultures: The Hofstede Model in Context. Online Readings in Psychology and Culture, 2 (1). https://doi.org/10.9707/2307-0919.1014

[8] Hofstede, G. (2001), Culture's Consequences: Comparing Values, Behaviors, Institutions, and Organizations Across Nations, 2nd ed. Sage, Thousand Oaks, CA. https://doi.org/10. $\underline{5465 / \mathrm{amr} .2002 .7389951}$

[9] Markus, H. R., \& Kitayama, S. (1991). Culture and the self: Implications for cognition, emotion, and motivation. Psychological Review, 98: 224-253. https://doi.org/10.1037/ 0033-295x.98.2.224

[10] Triandis, H. C. (2001). Individualism-collectivism and personality. Journal of Personality, 69: 908-942. https://doi.org/10.1111/1467-6494.696169

[11] Kabilan, M., Ganapathy, M., Bray, E., Gustine, G. \& Qasim, M. (2019). Facebooking” across Asia - Learning English along the way? Pertanika Journal of Social Science and $\mathrm{Hu}-$ manities, 27(1): 35-49.

[12] Carr, R., Olugbemiro J. J., Wong T., Yuen K. (1999). Asian Distance Learner. Hong Kong: Open University of Hong Kong Press.

[13] Murphy and Yuen (1999) IN Asian Distance Learner. Hong Kong: Open University of Hong Kong Press.

[14] Buraphadeja, V., \& Kumnuanta, J. (2011). Enhancing the sense of community and learning experience using self-paced instruction and peer tutoring in a computer-laboratory course. Australasian Journal of Educational Technology, 27(8): 1338- 1355. https://doi.org/10. 14742/ajet.897

[15] Ngampornchai, A., \& Adams, J. (2016). Students' acceptance and readiness for E-learning in Northeastern Thailand. International Journal of Educational Technology in Higher Education, 13 (1). https://doi.org/10.1186/s41239-016-0034-x

[16] Lévy, P. (2001). Cyberculture. University of Minnesota Press.

[17] Gunawardena, C. N. (2014). Globalization, culture, and online distance learning. In O. Zawacki Richter \& T. Anderson (Eds.), Online distance education-Towards a research 
Paper-Use of Digital Media in Higher Education across Country Contexts: A Comparison between...

agenda (pp. 75-107). Edmonton, Canada: Athabasca University Press. https://doi.org/10. 15215/aupress/9781927356623.01

[18] Bartosik-Purgat, M., Filimon, N., \& Kiygi-Calli, M. (2017). Social Media and Higher Education - A International Perspective. Economics \& Sociology, 10(1): 181-191. https://doi.org/10.14254/2071-789x.2017/10-1/13

[19] Dolch, C. (2020). Toys for the boys, tools for the girls? Gender and media usage patterns in higher education. Turkish Online Journal of Distance Education, 21: 94-111. https://doi.org/10.17718/tojde.762031

[20] National Statistical Office (2018). National Statistical Office. http://statbbi.nso.go.th/staticreport/page/sector/en/03.aspx

[21] DZHW (2019). German Centre for Higher Education Research and Science Studies. https://www.dzhw.eu/en

[22] Jürgens, A., \& Zinn, B. (2015). Nicht-traditionell Studierende in Deutschland - Stand der empirischen Forschung und Desiderate. In U. Elsholz (Hrsg.): Beruflich Qualifizierte im Studium. Analysen und Konzepte zum Dritten Bildungsweg. Bielefeld, S. 35-56. https://doi.org/10.3278/6004491w

[23] Rampelt, F., Orr, D., \& Knoth, A. (2019). Bologna Digital 2020: White Paper on Digitalisation in the European Higher Education Area. Hochschulforum Digitalisierung. https://doi.org/10.1007/978-3-030-56316-5 36

[24] CEPS (2019). Index of Readiness for Digital Lifelong Learning: Changing how Europeans upgrade their skills. Centre for European Policy Studies. https://www.ceps.eu/ wpcontent/uploads/2019/11/Index-of-Readiness-for-DigitalLifelong- Learning.PDF

[25] Grothaus, C., \& Zawacki-Richter, O. (2020). Collaborative online learning in the cultural context of South East Asia: A systematic review. Hacettepe University Journal of Education, Advance online publication. https://www./doi/10.16986/huje.2020062020

[26] Uzuner, S. (2009). Questions of Culture in Distance Learning: A Research Review. International Review of Research in Open and Distance Learning, 10(3). https://doi.org/ $\underline{10.19173 / \text { irrodl.v10i3.690 }}$

[27] Buckner E., Stein S. (2020). What Counts as Internationalization? Deconstructing the Internationalization Imperative. Journal of Studies in International Education, 24(2), 151-166. https://doi.org/10.1177/1028315319829878

[28] Hootsuite \& We Are Social (2018). Digital 2018 Thailand. https://datareportal.com/reports/digital-2020-thailand.

[29] DGA (2018). Digital Government Development Agency. Thailand. https://www.dga.or. $\underline{\text { th/en/ }}$

[30] United Nations (2018). United Nations Population Fund. https://www.unfpa.org.

[31] Council of University Presidents of Thailand (2018). Council of University Presidents of Thailand. https://www.cupt.net

[32] Atchariyachanvanich, K., Siripujaka, N., \& Jaiwong, N. (2014). What makes university students use cloud based E-learning? Case study of KMITL students. International Conference on Information Society: 112-116. https://doi.org/10.1109/i-Society, https://doi.org/10.1109 i-society.2014.7009022

[33] Pinpathomrat, N. ,Gilbert, L. \& Wills, G.B. (2013). A model of E-learning uptake and continued use in higher education institutions. International Association for Development of the Information Society: $423-427$.

[34] Punnoose, A. (2012). Determinants of intention to use eLearning based on the technology acceptance model. Journal of Information Technology Education: Research, 11(1), 301337. https://doi.org/10.28945/1744 
Paper-Use of Digital Media in Higher Education across Country Contexts: A Comparison between...

[35] Chaiprasurt, C., \& Esichaikil, V. (2013). Enhancing motivation in online courses with mobile communication tool support: A comparative study. The International Review of Research in Open and DistanceLearning, 14(3): 377-401. https://doi.org/10.19173/ irrodl.v14i3.1416

[36] Supanakorn-Davila, S., \& Bolliger, D. U. (2012). A preliminary evaluation of instructional effectiveness of online training implemented at a government agency in Thailand. International Journal on E-Learning, 11(1): 73-94.

[37] Laohajaratsang, T. (2009). E-Learning Readiness in the Academic Sector of Thailand. International Journal on E-Learning (iJeT), 8(4): 539-547.

[38] Siritongthaworn, S., \& Krairit, D. (2006). Satisfaction in e-learning: The context of supplementary instruction. Campus-Wide Information Systems, 23(2): 76-91. https://doi.org/ $\underline{10.1108 / 10650740610654465}$

[39] Teo, T., Luan, W. S., Thammetar, T., \& Chattiwat, W. (2011). Assessing e-learning acceptance by university students in Thailand. Australasian Journal of Educational Technology, 27(Special issue, 8): 1356-1368. https://doi.org/10.14742/ajet.898

[40] Teo, T., Ruangrit, N., Khlaisang, J., Thammetar, T., \& Sunphakitjumnong, K. (2014). Exploring e-learning acceptance among university students in Thailand: A national survey. Journal Education Computing Research, 50(4): 489-506. https://doi.org/10.2190/ec.50.4.c

[41] Grosch M. (2013). Media Use in Higher Education from a Cross-National Perspective. The Electronic Journal of eLearning, 11(3): 226-238.

[42] Bundesregierung. (2014). Digitale Agenda 2014 - 2017. Bundesregierung. https://www. bmwi.de/Redaktion/DE/Publikationen/Digitale-Welt/digitale-agenda.PDF.

European Commission Science and Knowledge Service (2019). The digital competence framework 2.0. Germany. https://ec.europa.eu/jrc/en/digcomp/digital-competence-frame work

[44] Hanft, A., Zawacki-Richter, O., \& Gierke, W. B. (Eds.). (2015). Herausforderung Heterogenität beim Übergang in die Hochschule. Waxmann.

[45] Pensel, S., \& Hofhues, S. (2017). Digitale Lerninfrastrukturen an Hochschulen. Systematisches Review zu den Rahmenbedingungen für das Lehren und Lernen mit Medien an deutschen Hochschulen. https://doi.org/10.13154/rub.104.93

[46] Steffens, Y., Schmitt, I. L., \& Aßmann, S. (2017). Mediennutzung Studierender: Über den Umgang mit Medien in hochschulischen Kontexten. Systematisches Review nationaler und internationaler Studien zur Mediennutzung Studierender. https://doi.org/10.1007/978-3531-19375-5 13

[47] Schäffer, D. (2015). E-Learning als Teil des persönlichen, intentionalen Lernraumes im Studium. Eine explorative Studie an Studierenden an der Fakultät für Erziehungswissenschaft an der Universität Bielefeld. Berlin: Epubli GmbH.

[48] Zawacki-Richter, O. (2015). Zur Mediennutzung im Studium - unter besonderer Berücksichtigung heterogener Studierender. Zeitschrift für Erziehungswissenschaft, 18(3): 527-549. https://doi.org/10.1007/s11618-015-0618-6

[49] Grosch, M., \& Gidion, G. (2011). Mediennutzungsgewohnheiten im Wandel: Ergebnisse einer Befragung zu studiumsbezogenen Mediennutzung [Changing media usage habits: Results of a survey on study-related media use]. Karlsruhe: KIT Scientific Publishing. https://publikationen.bibliothek.kit.edu/1000022524/175169

[50] Bogner A., Littig B., Menz W. (2009). Introduction: Expert Interviews - An Introduction to a New Methodological Debate. In: Bogner A., Littig B., Menz W. (eds) Interviewing Experts. Research Methods Series. Palgrave Macmillan, London. https://doi.org/10. $\underline{1057 / 9780230244276 \quad 1}$ 
Paper-Use of Digital Media in Higher Education across Country Contexts: A Comparison between...

[51] Grosch, M. (2014). About Student's Media Use for Learning in Tertiary Education Influence factors and Structures of Usage Behavior. International Journal on E-Learning, 13 (4): 415440.

[52] Harasim, L. (2012). Learning Theory and Online Technologies. New York/London: Routledge.

[53] Leekitchwatana, P. \& Pimdee, P. (2021). An Analysis of Thai Student Teacher Appropriate Internet Use Behaviour. International Journal of Emerging Technologies in Learning (iJET), 16 (02). https://doi.org/10.3991/ijet.v16i02.13747

[54] Pornwasin, A. Thailand is still number one for YouTube viewers in Southeast Asia. The Nation. https://www.nationthailand.com/business/30297423

[55] Leesa-Nguansuk, S. (2019). Thailand tops global digital rankings. Bangkok Post. https://www.bangkokpost.com/business/1631402/thailand-tops-global-digital-rankings

[56] Trompenaars, A., \& Hampden-Turner, C. (1998). Riding the waves of culture: Understanding cultural diversity in global business. New York: McGraw Hill.

[57] Komin, S. (1991). Psychology of the Thai People: Values and Behavioral Patterns,

[58] Köhl, M. \& Gotzenbrucker, G. (2014). Networked technologies as emotional resources? Exploring emerging emotional cultures on social network sites such as Facebook and Hi5: A trans-cultural study. Media, Culture \& Society, 36: 508-525. https://doi.org/10.1177/ $\underline{0163443714523813}$

\section{$7 \quad$ Authors}

Christin Grothaus is a $\mathrm{PhD}$ candidate in the Faculty of Education and Social Sciences at the University of Oldenburg. She is a lecturer and psychology minor program coordinator in the Faculty of Social Sciences at Mahidol University International College in Bangkok. She received her BA and MA in Educational Sciences (Diplom Pädagogik) with minors in Psychology and Sociology from the University of Hamburg.

Carina Dolch is a $\mathrm{PhD}$ candidate and Research Associate in the Faculty of Education and Social Sciences and Center for Lifelong Learning at the University of Oldenburg in Germany. She earned her B.A. in Sociology from the University of Hamburg (Germany) and her master's degree in Educational Science from the University Oldenburg.

Dr. Olaf Zawacki-Richter is Professor of Educational Technology at the University of Oldenburg in Germany. He is the Dean of the Faculty of Education and Social Sciences and Director of the Center for Open Education Research (COER).

Article submitted 2021-05-25. Resubmitted 2021-07-04. Final acceptance 2021-07-07. Final version published as submitted by the authors. 


\section{Appendix}

Table 5. Ranked acceptance of media, tools and services for learning in higher education

\begin{tabular}{|c|c|c|c|c|c|c|c|c|c|c|c|}
\hline $\mathbf{T}$ & G & & $\underline{\underline{M}}_{\mathrm{Th}}$ & $\mathbf{M}_{\mathrm{Ge}}$ & $\mathbf{n}_{\mathrm{Th}}$ & $\mathbf{n}_{\mathrm{Ge}}$ & $\mathbf{s}_{\text {Tha }}$ & $\mathbf{s}_{\mathrm{Ge}}$ & $\mathbf{T}$ & df & Sig \\
\hline 1 & 1 & Search engines $(\mathrm{W}, \mathrm{K}, \mathrm{L})$ & 4.57 & 4.71 & 187 & 1909 & 0.74 & 0.55 & 2.47 & 207 & .02 \\
\hline 2 & 2 & Instant Messaging $(\mathrm{W}, \mathrm{C}, \mathrm{L})$ & 4.38 & 4.49 & 185 & 1885 & 0.76 & 0.85 & 1.76 & 214 & .08 \\
\hline 3 & 14 & Videos $(W, L)$ & 4.24 & 3.61 & 187 & 1909 & 0.55 & 0.74 & -8.47 & 2062 & .00 \\
\hline 4 & 19 & Social Networks (W, C, L) & 4.14 & 3.20 & 188 & 1869 & 0.99 & 1.25 & -11.14 & 252 & .00 \\
\hline 5 & 4 & Email Account $(\mathrm{W}, \mathrm{C})$ & 4.12 & 4.32 & 187 & 1902 & 0.75 & 0.82 & 3.11 & 2087 & .00 \\
\hline 6 & 21 & $\operatorname{Music}(\mathrm{W}, \mathrm{L})$ & 4.06 & 3.22 & 184 & 1799 & 1.05 & 1.28 & -9.65 & 2423 & .00 \\
\hline 7 & 9 & Electronic Texts $(\mathrm{T})$ & 4.02 & 3.98 & 186 & 1923 & 0.91 & 0.82 & -0.54 & 2050 & .59 \\
\hline 8 & 16 & Online Translator (W) & 4.01 & 3.38 & 189 & 1841 & 0.84 & 0.89 & -8.93 & 2028 & .00 \\
\hline 9 & 3 & Word- processing programs $(\mathrm{E})$ & 3.95 & 4.33 & 179 & 1832 & 0.89 & 0.59 & 5.26 & 194 & .00 \\
\hline 10 & 5 & $\begin{array}{c}\text { Computer Working Spaces outside (at } \\
\text { home, at work) (E) }\end{array}$ & 3.94 & 4.26 & 180 & 1759 & 0.99 & 0.86 & 4.59 & 208 & .00 \\
\hline 11 & 7 & Internet based learning platform $(\mathrm{E}, \mathrm{C})$ & 3.91 & 4.03 & 179 & 1688 & 0.92 & 0.94 & 2.48 & 1865 & .01 \\
\hline 12 & 6 & PDF reader $(\mathrm{E})$ & 3.80 & 4.24 & 184 & 1879 & 0.93 & 0.70 & 6.33 & 204 & .00 \\
\hline 13 & 13 & Presen- tation software (E) & 3.78 & 3.72 & 181 & 1782 & 0.94 & 0.78 & -0.51 & 206 & .61 \\
\hline 14 & 22 & Online calendar $(\mathrm{W}, \mathrm{K})$ & 3.74 & 3.12 & 187 & 1739 & 1.08 & 1.40 & -6.51 & 2589 & .00 \\
\hline 15 & 10 & Printed texts $(T)$ & 3.62 & 3.86 & 174 & 1887 & 0.87 & 0.86 & 3.69 & 2059 & .00 \\
\hline 16 & 18 & Wikis (W, C, L) & 3.59 & 3.27 & 188 & 1634 & 0.95 & 0.99 & -3.52 & 1820 & .00 \\
\hline 17 & 46 & QR Code Scanner (W) & 3.59 & 2.04 & 185 & 1614 & 0.91 & 0.91 & -21.62 & 1979 & .00 \\
\hline 18 & 24 & $\begin{array}{c}\text { Computer Working spaces on the uni- } \\
\text { versity campus (E) }\end{array}$ & 3.58 & 3.03 & 180 & 1663 & 0.93 & 0.93 & -6.98 & 1841 & .00 \\
\hline 19 & - & $\begin{array}{l}\text { Computer Working spaces outsidel } \\
\text { (cafes, Co- working) (E) }\end{array}$ & 3.54 & & & & & & & & \\
\hline 20 & 33 & Presen- tation Sharing $(\mathrm{E})$ & 3.51 & 2.29 & 183 & 1063 & 0.92 & 0.93 & -15.52 & 1244 & .00 \\
\hline 21 & 25 & Cloud Computing $(\mathrm{W}, \mathrm{K})$ & 3.49 & 2.75 & 175 & 1141 & 1.12 & 1.26 & -6.41 & 247 & .00 \\
\hline 22 & 12 & Spread sheet software (E) & 3.42 & 3.72 & 174 & 1782 & 0.90 & 0.88 & 4.48 & 1954 & .00 \\
\hline 23 & 38 & Collabo- rative writing tools $(\mathrm{E}, \mathrm{C})$ & 3.40 & 2.17 & 180 & 1360 & 0.97 & 1.07 & -24.93 & 240 & .00 \\
\hline 24 & 20 & File sharing/ storage external $(\mathrm{E}, \mathrm{K}, \mathrm{C})$ & 3.39 & 3.22 & 170 & 1659 & 1.00 & 1.06 & -1.57 & 210 & .00 \\
\hline 25 & 8 & University Email account (E) & 3.35 & 3.96 & 184 & 1910 & 1.08 & 0.97 & 7.77 & 212 & .00 \\
\hline 26 & 17 & Lecture Recording (E) & 3.27 & 3.38 & & & & & & & \\
\hline 27 & 23 & File sharing/ storage internal $(\mathrm{E}, \mathrm{K}, \mathrm{C})$ & 3.25 & 3.08 & 170 & 1398 & 1.00 & 1.06 & -1.31 & 1569 & .19 \\
\hline 28 & 35 & $\begin{array}{c}\text { Free Multi- media based online learning } \\
\text { software (E) }\end{array}$ & 3.24 & 2.24 & 167 & 808 & 1.00 & 1.05 & -10.22 & 973 & .00 \\
\hline 29 & 42 & Mind map Tools (E) & 3.23 & 2.12 & 164 & 1484 & 1.08 & 1.00 & -11.03 & 195 & 0.00 \\
\hline 30 & 55 & Micro- Blogging $(\mathrm{W}, \mathrm{C})$ & 3.20 & 1.53 & 183 & 1577 & 1.25 & 0.88 & -17.31 & 204 & .00 \\
\hline 31 & - & Video calls $(\mathrm{W}, \mathrm{C})$ & 3.20 & & & & & & & & \\
\hline 32 & 37 & Podcasts/ Video Podcast (E) & 3.18 & 2.17 & 173 & 1162 & 1.10 & 1.09 & -10.38 & 1333 & .00 \\
\hline 33 & 32 & Graphic Software (E) & 3.15 & 2.47 & 171 & 1299 & 1.00 & 1.06 & -6.71 & 1468 & .00 \\
\hline 34 & 28 & Online exams/test (E) & 3.10 & 2.64 & 117 & 736 & 0.94 & 0.89 & -11.39 & 851 & .00 \\
\hline 35 & 15 & Online library services $(\mathrm{E})$ & 3.09 & 3.52 & 171 & 1742 & 0.94 & 0.79 & 6.17 & 19 & .00 \\
\hline 36 & - & Virtual bulletin board/pin board (E, C) & 3.08 & & & & & & & & \\
\hline
\end{tabular}


Paper-Use of Digital Media in Higher Education across Country Contexts: A Comparison between...

\begin{tabular}{|c|c|c|c|c|c|c|c|c|c|c|c|}
\hline 37 & 41 & Video software (E) & 3.07 & 2.13 & 173 & 1148 & 0.99 & 0.97 & -10.68 & 1319 & .00 \\
\hline 38 & 26 & Forums, News- groups $(\mathrm{W}, \mathrm{C})$ & 3.06 & 2.47 & 174 & 1503 & 0.96 & 0.94 & -6.94 & 1675 & .00 \\
\hline 39 & 11 & Courses' e-mailing list (E) & 3.05 & 3.75 & 164 & 1766 & 1.10 & 0.87 & 7.86 & 182 & .00 \\
\hline 40 & 30 & Statistic software (E) & 3.01 & 2.53 & 130 & 1012 & 0.99 & 0.95 & -4.57 & 1140 & .00 \\
\hline 41 & 50 & Audience Response Tools (E) & 2.98 & 1.86 & 162 & 1003 & 1.04 & 1.03 & -12.00 & 249 & .00 \\
\hline 42 & 34 & Software for qualitative text analysis (E) & 2.97 & 2.25 & 119 & 673 & 1.00 & 0.99 & -6.71 & 790 & .00 \\
\hline 43 & 26 & University Internal forums/ groups (E,C) & 2.97 & 2.70 & 163 & 1360 & 1.07 & 1.01 & -2.41 & 1521 & .02 \\
\hline 44 & 29 & $\begin{array}{l}\text { Virtual Seminars Webinar tools, live } \\
(\mathrm{E}, \mathrm{C})\end{array}$ & 2.93 & 2.59 & 150 & 1077 & 1.01 & 1.00 & -3.18 & 1225 & .00 \\
\hline 45 & 43 & MOOC's (E) & 2.91 & 2.11 & 116 & 354 & 1.04 & 1.06 & -5.60 & 468 & .00 \\
\hline 46 & 27 & Literature Adminis- tration software $(\mathrm{E})$ & 2.90 & 2.68 & 120 & 1067 & 1.03 & 1.01 & -1.26 & 1185 & .21 \\
\hline 47 & 36 & $\begin{array}{c}\text { Business } \\
\text { Networks (W) }\end{array}$ & 2.86 & 2.23 & 159 & 1348 & 1.00 & 1.06 & -6.29 & 202 & .00 \\
\hline 48 & 45 & Audio software $(\mathrm{E})$ & 2.86 & 2.08 & 162 & 1003 & 1.04 & 1.03 & -7.76 & 1163 & .00 \\
\hline 49 & - & Virtual Worlds (E) & 2.82 & & & & & & & & \\
\hline 50 & 40 & Simulation or education. games (E) & 2.82 & 2.17 & 151 & 872 & 1.09 & 0.95 & -6.08 & 191.05 & .00 \\
\hline 51 & 44 & $\mathrm{Blogs}(\mathrm{W}, \mathrm{C})$ & 2.80 & 2.11 & 148 & 1553 & 1.02 & 1.01 & -7.56 & 1699 & .00 \\
\hline 52 & 39 & Virtual labs $(\mathrm{E}, \mathrm{C})$ & 2.73 & 2.17 & 143 & 629 & 1.08 & 0.98 & -4.73 & 770 & .00 \\
\hline 53 & 54 & RSS-Feeds (W) & 2.65 & 1.74 & 112 & 735 & 1.01 & 0.98 & -8.73 & 845 & .00 \\
\hline 54 & 48 & Photo Commu- nities $(\mathrm{W}, \mathrm{C})$ & 2.62 & 1.96 & 157 & 1697 & 1.08 & 1.14 & -6.70 & 1852 & .00 \\
\hline 55 & 47 & Skype as $1: 1$ Conversat on $(\mathrm{W}, \mathrm{C})$ & 2.39 & 2.02 & 173 & 1511 & 1.02 & 0.95 & -4.32 & 1729 & .00 \\
\hline 56 & 53 & Skype as Group Confe- rence $(\mathrm{W}, \mathrm{C})$ & 2.34 & 1.95 & 173 & 1558 & 1.02 & 0.95 & -4.54 & 1682 & .00 \\
\hline
\end{tabular}

Types of media: $\mathrm{W}=$ general web tools and services; $\mathrm{E}=$ e-learning tools and services, $\mathrm{C}=$ collaborative web and learning tools, $\mathrm{L}=$ Tools for leisure and entertainment 